
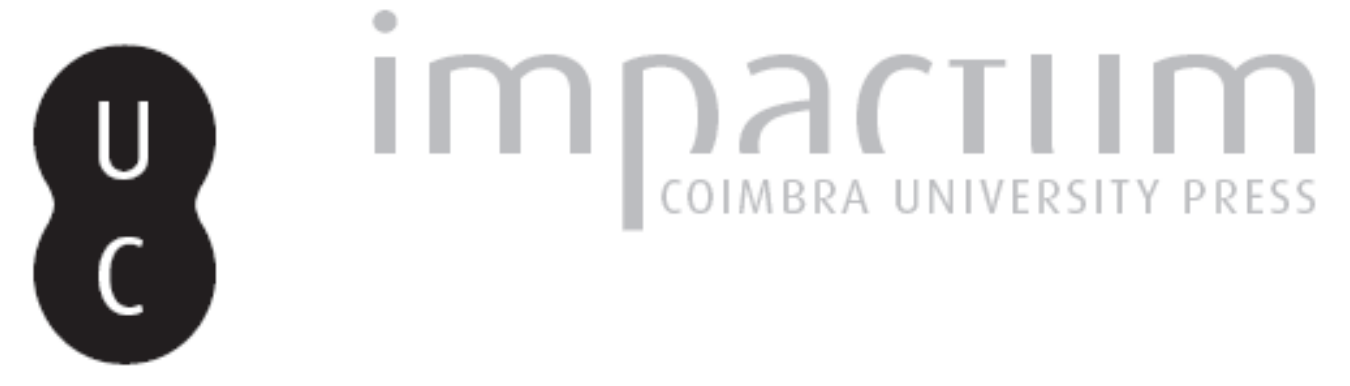

\title{
Estudos camonianos em Itália
}

\section{Autor(es): Miraglia, Gianluca}

Publicado por: Imprensa da Universidade de Coimbra

URL persistente:

URl:http://hdl.handle.net/10316.2/42688

DOI:

DOl:https://doi.org/10.14195/0870-8584_1_7

Accessed : $\quad$ 26-Apr-2023 11:18:57

A navegação consulta e descarregamento dos títulos inseridos nas Bibliotecas Digitais UC Digitalis, UC Pombalina e UC Impactum, pressupõem a aceitação plena e sem reservas dos Termos e Condições de Uso destas Bibliotecas Digitais, disponíveis em https://digitalis.uc.pt/pt-pt/termos.

Conforme exposto nos referidos Termos e Condições de Uso, o descarregamento de títulos de acesso restrito requer uma licença válida de autorização devendo o utilizador aceder ao(s) documento(s) a partir de um endereço de IP da instituição detentora da supramencionada licença.

Ao utilizador é apenas permitido o descarregamento para uso pessoal, pelo que o emprego do(s) título(s) descarregado(s) para outro fim, designadamente comercial, carece de autorização do respetivo autor ou editor da obra.

Na medida em que todas as obras da UC Digitalis se encontram protegidas pelo Código do Direito de Autor e Direitos Conexos e demais legislação aplicável, toda a cópia, parcial ou total, deste documento, nos casos em que é legalmente admitida, deverá conter ou fazer-se acompanhar por este aviso.

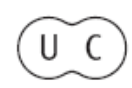




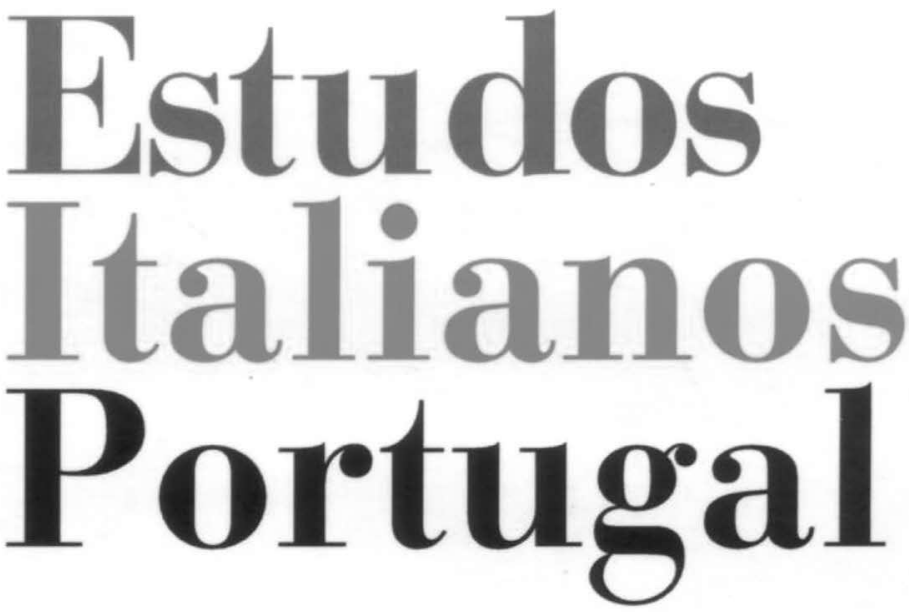

Instituto

Italiano

de Cultura

em Portugal

Nova Série

$\mathbf{N}^{\circ} \mathbf{1}$

2006 


$\begin{array}{llll}\text { 22. (59) } & 1543 \quad 8 \text { Março } & \text { Roma } & \text { Paulo III } \\ \text { 23. (60) } & 1543 \text { ? } & \text { Roma } & \begin{array}{l}\text { Leandro de Albertis } \\ \text { 24. (61) }\end{array} 1543 \text { ? } \\ & & \text { Roma } & \begin{array}{l}\text { Johannes Baptista } \\ \text { Rhamusio }\end{array} \\ \text { 25. (- -) } & \text { 1543 21 Maio } & \text { Roma } & \text { Damianus a Goes } \\ \text { 26. (62) } & 1543 \text { Outubro } & \text { Roma } & \text { Segismundo I } \\ \text { 27. (63) } & 1543 \text { Outubro } & \text { Roma } & \text { Bispo de Plocz } \\ \text { 28. (64) } & 1544 \text { Janeiro } & \text { Roma } & \text { Paulo III } \\ \text { 29. (65) } & 1544 \text { 4 Março } & \text { Roma } & \text { Paulo III }\end{array}$

\section{ESTUDOS CAMONIANOS EM ITÁLIA*}

\section{Gianluca Miraglia}

ENTRE AS NUMEROSAS PUBLICAÇÕES vindas à luz em 1972, por ocasião do IV centenário da editio princeps de Os Lusíadas, destaca-se, no âmbito dos estudos sobre a difusão da obra de Camões no mundo, o livro de G. Manuppella, Camoniana Itálica ${ }^{1}$ É um levantamento bibliográfico amplo, minucioso e exaustivo que abrange a crítica literária, a criação poética e narrativa, o teatro, as artes e a música, repercorrendo a presença e a recepção do poeta quinhentista na cultura italiana ao longo dos séculos. Passados aproximadamente trinta anos, é altura certa para, em jeito de addenda, dar breve notícia, que não se pretende porém completa, dos estudos camonianos em Itália, dando a esta expressão um sentido mais lato que engloba todos os artigos de autores italianos editados nas últimas três décadas, independentemente do seu local de publicação.

Seguindo a ordem cronológica, podemos começar pelo ano de 1975, ano em que J.V. de Pina Martins organizou em Roma uma importante exposição bibliográfica, que teve

* O texto reproduz, com actualização bibliográfica, a comunicação apresentada no IX Fórum Camoniano: 1. A projecção universal de Camões, 2. O ensino de Camões hoje, Centro Internacional de Estudos camonianos da Associação da Casa-Memória de Camões em Constância, 26 e 27 de Julho de 2001.

${ }^{1}$ Camoniana Itálica: subsídios bibliográficos, Coimbra, Instituto Estudos Italianos, 1972. 
como precioso testemunho um magnífico catálogo com introdução de L. Stegagno Picchio ${ }^{2}$, enquanto A. Roncaglia proferiu uma conferência na Accademia dei Lincei com o título de I Lusiadi di Camões nel quarto centenário ${ }^{3}$.

Cinco anos mais tarde, em 1980, data que assinalava o IV centenário da morte do poeta, registam-se numerosos estudos coligidos, na sua quase totalidade, em três publicações: Studi Camoniani $80^{4}$, Brotéria ${ }^{5}$, e Arquivos do Centro Cultural Português ${ }^{6}$. Vejamos em primeiro lugar a revista italiana que traz como subtítulo "contributo alle celebrazioni del centenario di Camões". Dos seis artigos que compõem o volume, os primeiros quatro são consagrados à épica. E. Finazzi-Agrò colabora com um estudo sobre um aspecto particular do poema, "I Lusiadi e gli altri (contatti tra culture e tra lingue nell'epos camoniano: la figura dell'interprete)", enquanto E. Melillo Reali analisa a estrofe XXVI do Canto IX no seu artigo "Atteone e il re". "Considerazioni su Ariosto e Camões”, de L. Rossi, salienta e exemplifica a rica e complexa intertextualidade temática e estilística entre os dois poetas quinhentistas, um aspecto que, diga-se en passant, muitas vezes os textos escolares e didácticos descuram, ao reduzir e esgotar a relação entre os dois escritores num comentário empobrecedor da estrofe XI do canto I que enfatiza a contraposição entre verdade, o "vi claramente visto" camoniano, e fantasia ariostesca, numa clara desvalorização do autor italiano ${ }^{7}$.

2 Camões e il Rinascimento Italiano: mostra bibliográfica, Roma, 1975.

3 Accademia Nazionale dei Lincei, Celebrazioni Lincee, fascicolo 88, 1975.

Studi Camoniani 80: contributo alle celebrazioni del centenário de Camões, a cura di G. Lanciani, Romanica Vulgaria Quaderni 2, L'Aquila, Japadre, 1980.

${ }^{5}$ Vol. III, nº1/2/3, Julho-Agosto-Setembro 1980, e vol. III, n. ${ }^{\circ}$ 5, Novembro 1980 .

${ }^{6}$ Vol. XVI, Camões, F.C.G., Paris, 1981

Acerca da atitude da crítica portuguesa em relação ao Orlando Furioso veja-se J. da Costa Miranda, "Camões / Ariosto: um confronto evidente no percurso do Orlando Furioso em Portugal”, in Luís de Camões, Rime, scelte, tradotte e
O quarto artigo é de G. Tavani, "A proposito del vecchio del Restelo", uma análise do episódio contido nas últimas oitavas do canto IV que visa, por um lado, pôr em relevo o seu papel na economia geral do poema e, por outro, desvendar em termos sócio-históricos, com base nas teorias de Bachtin, quem ou mais precisamente que grupo social fala por boca do velho venerando. A concluir o volume, dois artigos sobre o teatro, "Sul conflitto tra amore contemplativo nel teatro camoneano" e "Il Seleuco di Camões: disgregazione e parodia d'una leggenda d'amore", respectivamente de C. Donati e de G. Lanciani.

$\mathrm{Na}$ revista Brotéria, mais precisamente no número 1/2/3 de Julho-Agosto-Setembro e no número 5 de Novembro, foram editadas as actas do Encontro Internacional de Estudos Camonianos, promovido pela Fundação Mateus. Participaram no colóquio G. Carlo $\mathrm{Rossi}^{8}$, com "O meu Camões"; E. Melillo Reali, que em "Camões e Dom Sebastião" retoma e desenvolve o artigo anteriormente publicado em Studi Camoniani 809; E. Finazzi Agrò, "A epifania do herói

commentate da R. Averini, Estudos Italianos em Portugal, Numero speciale pubblicato in occasione del quarto centenário della morte di Luís de Camões, Lisbona, 1979. Para uma posição crítica diferente sobre a relação Ariosto-Camões veja-se H.J.S.Alves, Camões, Corte-Real e o sistema da epopeia quinhentista, Coimbra, 2001, que afirma: "No caso de Camões, a despeito de todos os esforços de encobrimento ou recusa patentes no seu poema e de, por razões relacionadas com as normas da poética aristotélica, Severim de Faria, Faria e Sousa e os críticos sucessores terem evitado a comparação do seu ídolo com a herança ferraresa, observa-se de facto que o Orlando Furioso é o mais importante modelo poético d'Os Lusíadas, a par da epopeia virgiliana"(p.334). Acrescente-se que hoje em dia o leitor português não dispõe de versões, sequer parciais, do poema de Ariosto.

${ }^{8}$ Do mesmo autor, As traduções italianas de Os Lusíadas, Lisboa, Comissão Executiva IV Centenário, 1973.

${ }^{9}$ Convém dizer que a sugestiva interpretação dos versos camonianos mereceu alguns reparos por parte de A. Costa Ramalho, segundo o qual a estudiosa italiana não teve em devida conta a realidade concreta da corte portuguesa nos anos de governo do jovem rei, cf. Colóquio-Letras, n 63, Setembro 1981. 
na Ilha dos Amores"; A. Tabucchi, "Tipologia da súplica em Os Lusíadas", G. Lanciani, "O Seleuco de Camões: desagregação e paródia de uma lenda de amor", que é a versão portuguesa do artigo publicado em Studi Camoniani 80; G. Tavani, "A estrutura espácio-temporal de 'Os Lusíadas"”, uma comunicação por vários aspectos polémica dado que o autor questiona, com base na análise detalhada das estruturas espaço-temporais do poema, o estatuto épico de Os Lusíadas; e finalmente L. Rossi, "Considerações sobre Ariosto e Camões", versão portuguesa do artigo publicado em Studi Camoniani 80.

Nos Arquivos do Centro Cultural Português, registamos um artigo sobre a lírica, de Aurélio Roncaglia, "Couleurs de peinture et couleurs de rhetorique dans la poesie lyrique de Camões", o texto de L. Stegagno Picchio "O canto molhado", interpretação das estrofes CXXVII-CXXVIII do Canto $\mathrm{X}^{11}$ e de G. Tavani, "Ainda sobre a estrutura espácio-temporal de Os Lusíadas". Este último estudo merece uma pequena anotação. Como indica o título, trata-se do desenvolvimento da comunicação apresentada no Encontro Internacional de Estudos Camonianos, motivado por artigo de V. Graça-Moura, entretanto publicado no Diário de Notícias (e sucessivamente recolhido no volume Luís de Camões: alguns desafios), que refutava a argumentação do crítico italiano. Na réplica, Tavani retoma e esclarece a sua posição para no fim acrescentar outra provocação teórica, ao subli-

${ }^{10}$ Do mesmo autor lembramos "Il mal del tempo. Considerazioni sul manierismo di Camões", in Spicilegio Moderno, II, 1973.

11 De L. Stegagno Picchio registe-se também "Biografia e autobiografia. Due studi in margine alle biografie camoniane ("O canto molhado", "Super Flumina»", in Quaderni Portoghesi, 7-8, Primavera- Autunno 1980; "Super flumina Babylonis: ispirazione tematica e ispirazione formale nel canto di schiavitù del poeta Luís Vaz de Camões", in Quaderni Portoghesi, Roma-Pisa, 7-8, 1981, e anteriormente, "Ars combinatoria e algebra delle proporzioni in una lirica di Camões”, in Studi Romanzi, XXXV, 1973. nhar a presença no poema do cómico, que, no seu entender, "por definição é a antítese do épico"12.

Nos anos sucessivos à efeméride, que, como vimos, esteve na origem de uma abundante e variada produção crítica, os estudos camonianos de autores italianos tornam-se progressivamente menos numerosos. Com efeito, para a década de 80, podemos assinalar um texto do latinista F. Della Corte "Narrativistica virgiliana n'Os Lusíadas"13; dois artigos de A. Martinengo, nomeadamente a comunicação apresentada na IV Reunião Internacional de Camonistas, que se realizou em Ponta Delgada, "Três sonetos quinhentistas em Louvor de Camões"14, e o estudo para o volume colectivo editado pela Academia das Ciências sobre a projecção da obra camoniana em culturas e literaturas estrangeiras, "Fortuna di Camões in Itália"15; e finalmente o volume de G. Lanciani, Mito ed esperienza nella nomenclatura geografica dei Lusiadi ${ }^{16}$.

Em relação aos anos 90, destaca-se a actividade de L. Stegagno Picchio, testemunho de uma dedicação à obra camoniana que persiste ao longo do tempo, com os artigos “... Turricano, chi era costui? Nota in margine al sonetto di Torquato Tasso per Vasco da Gama e Luís de Camões"17, “Teatralização dos Descobrimentos: Os Lusíadas na corte

12 Os dois textos podem ser agora lidos no volume Ensaios Portugueses, Imprensa Nacional-Casa da Moeda, 1988.

13 In Virgílio e a cultura portuguesa: Actas do bimilenário da Morte de Virgílio, Lisboa, 1981.

${ }^{14}$ In Actas da IV Reunião Internacional de Camonistas, Ponta Delgada, Universidade dos Açores, 1984.

15 Estudos sobre a projecção de Camões em culturas e literaturas estrangeiras, Academia das Ciências, 1984. A. Martinengo publicara em 1954 um notável levantamento bibliográfico, Fortuna di Camões in Itália, obra de referência obrigatória até ao aparecimento da Camoniana Itálica.

16 Cisalpino-Goliardica, 1984.

17 In Studi di filologia e letteratura italiana in onore di Maria Picchio Simonelli, ed. P. Frassica, Alessandria, Edizioni dell'Orso, 1992. 
del-Rey Dom Sebastião"18 " "O thíasos marinho na literatura portuguesa de Gil Vicente a Gonzaga"19, e as comunicações "Camões lírico: variantes de tradição e variantes de autor. Achegas para o estudo da movência em textos camonianos" 20 , e "O mito de Camões" 21

Finalmente, para os anos mais recentes, registamos o aparecimento de outros lusitanistas que asseguram continuidade à contribuição italiana para os estudos camonianos, trata-se de B. Spaggiari, que apresentou no I Congresso Internacional de Estudos Camonianos de Rio de Janeiro ${ }^{22}$ a comunicação "Algumas considerações sobre a língua de Camões", e noutro colóquio analisou "La censure dans la transmission de l'ouevre de Luís de Camões"23, e de V. Tocco, "Modu-

${ }^{18}$ In Adágio, Revista de Arte e Cultura, ano II, série I, n. 8 Evora, 1992.

${ }_{19}$ In Studies in Portuguese Literature and History in Honour of Luís de Sousa Rebelo, ed. Helder Macedo, London, Tamesis Book Limited, 1992, sucessivamente reeditado no livro da autora Mar Aberto, Lisboa, Caminho, 1999.

${ }^{20}$ In Actas da V Reunião de Camonistas, São Paulo, 1992.

21 In Reunião Internacional de Camonistas, Coimbra, Abril, 1996.

22 Rio de Janeiro, 1998. De B. Spaggiari, que na realidade se ocupa desde há muito da lírica camoniana, registe-se igualmente o ensaio "Nel quarto centenario della morte di Luís de Camões: L'ode IX: per la conoscenza della lirica camoniana”, in Annali della Scuola Normale Superiore di Pisa. Classe di Lettere e Filosofia, Serie 3, Pisa, 1980; a introdução e as notas à sua versão de L. de Camões, Ode IX: fogem as neves frias, Edizione dell'Arquate, 1990, e finalmente "O Renascimento italiano e a lírica de Camões", in O Renascimento italiano e a poesia lírica de Camões, Rio de Janeiro, Tempo Brasileiro, 1992. Acerca das relações entre Petrarca e as literaturas ibéricas registam-se igualmente M. Perugi, "Pétrarque dans la Renaissance portugaise et ibérique: quelques réflexions": Genève et l'Italie. Études publiées à l'occasion du 75. et 80. anniversaire de la Société Genevoise d'Études Italiennes, sous la direction d'Angela Kahn-Laginestra, Genève, Société Genevoise d'Études Italiennes, v. 2, 1999, e G. Poggi, "Cadeias de vida, cadeias de amor. Para o estudo de um motivo petrarquista nas letras ibéricas", in Petrarca 700 anos, coordenação de Rita Marnoto, Instituto de Estudos Italianos da Faculdade de Letras de Coimbra, Coimbra, 2005.

${ }^{23}$ In Censure et Littérature dans le pays de langues romanes, ed. C. Le Bigot e Y. Panafieu, Rennes, Presses de l’Université, 2000. lazioni ecfrastiche nei Lusíadas de Camões"24, e "Camões di fronte agli italiani" 25 .

Considerando no seu conjunto os estudos camonianos em Itália das últimas três décadas, podemos afirmar que o contributo italiano para a análise e interpretação crítica da obra de Camões é, sem dúvida, significativo e ao mesmo tempo diversificado: sobressai como âmbito privilegiado de investigação a épica, mas a lírica, com particular incidência nas redondilhas "Sôbolos rios", e o teatro não são de modo algum descurados. Menos numerosos os artigos que abordam as relações entre Camões e a literatura italiana, área para a qual o volume de Manuppella abrira várias pistas de investigação e que tem sido mais explorada, em tempos recentes, pelos italianistas portugueses, como demonstram os trabalhos de J. da Costa Miranda ${ }^{26}$, de H. de Almeida Chaves ${ }^{27}$ e finalmente de R. Marnoto ${ }^{28}$, que para além de ter delineado um

${ }^{24}$ In AA.VV., Lettere e Arti nel Rinascimento, Chianciano-Pienza, Nuovi Orizzonti, 2001.

25 In AA.VV., Rapporti e scambi tra Rinascimento italiano e Rinascimento europeo, Chainciano-Pienza, Nuovi Orizzonti, 2001. De V. Tocco, veja-se agora o volume A Lira Destemperada. Estudos sobre a tradição manuscrita de "Os Lusíadas", Adriática Editrice, Bari, 2005.

26 "Alguns apontamentos para um futuro estudo sobre Bernardo Tasso em Portugal”, Arquivos do Centro Cultural Português, XIII, Paris, 1978; Estudos luso-italianos: poesia épico-cavaleiresca e teatro setecentista, Lisboa, ICALP, 1990.

27 A recepção literária do mito de Camões em Itália, Universidade Nova de Lisboa, 1997.

28 “Camões, Laura e a Bárbora escrava”, in Máthesis, 6, 1997; O Petrarquismo português do renascimento e do Maneirismo, Coimbra, Imprensa da Universidade, 1997; "Da Arcádia a Sôbolos Rios", in Actas do V Congresso da Associação Internacional de Lusitanistas, Oxford-Coimbra, 1998; "Petrarca em redondilha", in Dynamique d'une Expansion Culturelle. Petrarque en Europe. XIV-XX siècle. Actes du XXVI Congrès Internacional du CEFI, Turin et Chambéry, 11-15 décembre 1995. A la mémoire de Franco Simone, études réunies et publiées par Pierre Blanc, Paris, Honoré Champion, 2001; "A ambivalência da mimicry. Leituras da Bárbora escrava", Revista Camoniana, 3. a série, 14, 2003 ; "O dissídio camoniano: fractura e significação", Congresso Internacional de Lexicografia e Literaturas no Mundo 
quadro exaustivo da difusão do petrarquismo na literatura portuguesa renascentista e maneirista, tem abordado, em vários artigos a relação entre Petrarca e Camões.

Não será inoportuno relembrar que é este um tema delicado, complexo que a crítica camoniana nem sempre conseguiu encarar e analisar de forma isenta, ou segundo uma metodologia adequada ao tipo específico de relação intertextual entre o Canzoniere e as Rimas. Por vezes, a relação é pura e simplesmente ignorada, e dir-se-ia pour cause, como se verifica nas páginas da crítica romântica, de cariz nacionalista, e da crítica idealista. Outras vezes, e mesmo em estudos mais recentes, a comparação entre a obra poética dos dois escritores é de algum modo finalizada no sentido de demonstrar a superioridade da lírica de Camões, mas, neste caso, a descrição quer da obra de Petrarca, quer do fenómeno multifacetado do petrarquismo aparece quase sempre drasticamente simplificada. Na realidade, o que está na origem da dificuldade de equacionar de forma correcta a relação entre Petrarca e Camões é o problema mais geral que a leitura e interpretação das obras do classicismo coloca ao leitor moderno, herdeiro malgré lui da revolução romântica. Com efeito, como escreve A. Quondam, "solo dopo un lungo e faticoso lavoro di scavo e di restauro (in senso compiutamente archeologico) di tutti gli ingredienti del loro atto comunicativo siamo in grado di approssimare il senso originario e proprio di questi testi, e di valutarne sia il progetto che l'esecuzione iuxta propria principia, sempre che riusciamo a liberarci dell'istintivo fastidio per l'imitazione e la tradizione, il riuso e le regole (ivi comprese le forme metriche regolari), sempre che riusciamo a liberarci dell'altrimenti istintiva, e assurdamente limitativa, valutazione secondo cui

Lusofônico (de 17 a 21 de Julho de 2000), organização de L.A. de Azevedo Filho, Rio de Janeiro, Agora da Ilha, 2002; "Camões. A ordem dos clássicos e o ruído de fundo", Aprendizagem Desenvolvimento, 10, 39-40, 2005. queste opere sarebbero belle nonostante i criteri (di forma e di norma) e le intenzioni con cui sono state prodotte" 29 . Pelo contrário, em certa crítica camoniana a distância em relação à obra classicista, a fractura entre a estética do tempo e a estética moderna, parece dissolver-se, de modo que o discurso crítico acaba por permanecer no âmbito das coordenadas do que A. Quondam define como "paradigma storiografico e critico dell'Antico Regime e del Classicismo" segundo o qual "nonostante l'ossessivo dominio delle regole [...] nonostante tutto ciò che ha vincolato e limitato la 'libertà' creativa dell'artista e che ha minato l'irrinunciabile diritto della sua fantasia all'originalità e della sua opera al copyright" alguns autores "sono riusciti a diventare, cioè ad essere considerati, grandi scrittori" 30 . Neste sentido, aliás, parece-me que a "tentação de ler a lírica camoniana em clave biográfica", ou seja "a ilusão biografista” de tantas páginas críticas, que como demonstra V. Aguiar e Silva enraíza no próprio código petrarquista que conjuga imitatio vitae e imitatio stili ${ }^{31}$, pode ser talvez reconduzida a uma estratégia, consciente ou menos, que, ao contornar o problema hermenêutico e ao estabelecer uma dicotomia entre génio, entendido numa concepção quase romântica, e concretos meios expressivos, visa subtrair o escritor aos códigos poéticos do seu tempo como se a eles o poeta tivesse sido obrigado a sujeitar-se por meros motivos comunicacionais.

Por estas razões devem ser realçados os estudos de R. Marnoto, alicerçados num profundo conhecimento da obra de Petrarca e do petrarquismo nas suas várias manifestações e enquadrados numa hermenêutica ciente da diferença entre

29 A.Quondam, "Note su imitazione, furto e plagio nel Cinquecento", in AA.VV, Furto e plagio nella letteratura del Classicismo, a cura di R. Gigliucci, Roma, Bulzoni Editore, 1998, p. 376.

30 Ivi, p. 377.

31 Cf. V.M. Aguiar e Silva, Camões: Labirintos e fascínios, Lisboa, Cotovia, 1994 (em particular o capítulo "Aspectos petrarquistas da lírica”). 
clássicos e modernos, que não só recolocam a obra camoniana no espaço que é o seu, mas através duma minuciosa exegese dos textos camonianos põem em luz como o encontro entre o modelo petrarquista e a poesia de Camões dá origem a uma transformatio inovadora que encontra a sua melhor exemplificação no canto, aliás em verso tradicional, de uma figura feminina em que "beleza fisica e beleza espiritual integram-se numa harmonia perfeita, sem sobressaltos, à luz de um neoplatonismo firmado a partir da conciliação entre terreno e incorpóreo".

Se nos referirmos agora à projecção de Camões em Itália, propriamente dita, as considerações a tecer são menos positivas, ou seja, apesar da notável actividade crítica, a divulgação da obra entre um público mais alargado continua a ser diminuta e a própria figura humana e mítica do autor bem conhecida no século XIX resulta hoje em dia quase esquecida. A impressão é, aliás, que a leitura da obra camoniana permanece circunscrita substancialmente ao meio académico, senão mesmo aos departamentos de Iberística, como parece indicar o levantamento aqui apresentado que regista apenas um artigo não escrito por lusitanistas. É óbvio que, para dar à obra camoniana uma visibilidade comparável à dos outros grandes vultos da literatura universal, afigura-se fundamental e insubstituível o papel das traduções. Em relação ao poema épico, do qual em 1972 tinham sido editadas duas versões, uma de autoria de E. di Poppa Volture ${ }^{32}$, outra de R. Averini ${ }^{33}$, assinalamos como iniciativa meritória a nova edição desta última, agora bilingue em dois volumes, com notas de V. Tocco e introdução de G. Mazzocchi ${ }^{34}$, integrada numa prestigiada colecção de autores clássicos com ampla difusão. Pelo que diz respeito à lírica, a antolo-

32 Luís de Camões, I Lusiadi, Firenze, Sansoni, 1972.

${ }^{33}$ Luís de Camões, I Lusiadi, Milano, Mursia, 1972.

${ }^{34}$ Milano, BUR Rizzoli, 2000. gia organizada por R. Averini em 1979, que é na verdade uma apresentação modelar da poesia camoniana ao leitor italiano, quer pela introdução quer pelo comentário que acompanha os textos escolhidos ${ }^{35}$, encontra-se desde há muito esgotada. Resta dizer que, sem com isso pretender retirar mérito algum às versões de $\mathrm{R}$. Averini e não excluindo outros motivos que possam explicar a limitada projecção da obra de Camões em Itália, talvez ainda não se tenha verificado, e penso sobretudo na lírica, um feliz encontro entre textos originais e tradutor capaz de fazer reviver em língua italiana, na sua plenitude, a expressão única e inimitável da poesia camoniana.

${ }^{35}$ Luís de Camões, Rime, scelte, tradotte e commentate da R. Averini, Estudos Italianos em Portugal, Numero speciale pubblicato in occasione del quarto centenário della morte di Luís de Camões, Lisbona, 1979. 